No. 2011-027

\title{
Reproductive Health Aid: A Delicate Balancing Act
}

\author{
By Hendrik P. van Dalen and Maja Micevska Scharf
}

23 February 2011

ISSN 0924-7815 


\title{
Reproductive Health Aid: A Delicate Balancing Act
}

\author{
Hendrik P. van Dalen ${ }^{\mathrm{a}, \mathrm{b}}$ and Maja Micevska Scharf ${ }^{\mathrm{b}}$
}

February 23, 2011

\author{
(a) Tilburg University \\ Department of Economics \\ P.O. Box 90153 \\ NL-5000 LE Tilburg \\ The Netherlands \\ (b) Netherlands Interdisciplinary Demographic Institute (NIDI) \\ P.O. Box 11650 \\ NL-2502 AR The Hague \\ The Netherlands \\ Email: dalen@nidi.nl
}

Keywords: health, development aid, AIDS, fertility

JEL-codes: F35, I18, H87

\begin{abstract}
In this contribution the authors show that development assistance targeting reproductive health overwhelmingly concentrates on HIV/AIDS at the expense of family planning elements. Data on financial contributions disbursed by governments and private foundations are used as collected by the Resource Flows project as initiated by UNFPA/NIDI. The current allocation of aid does not accord well with the plans made in Cairo at the International Conference on Population and Development in 1994. Part of the explanation is that future health needs are difficult to predict, but it also shows how strong the influence of one donor, i.e. the United States, is in this setup. The landscape of population assistance is a highly volatile one, brought about not only by political issues like the Global Gag Rule, but also issues of collective action design as assistance under the heading of the Millennium Development Goals crowds out family planning. A complicating factor is that development assistance for reproductive health is at some points ill-adjusted towards the needs of developing countries.

* Forthcoming in: A. Kulczycki (ed.), Critical Issues in Reproductive Health, Springer, New York.
\end{abstract}




\section{Introduction}

“All countries should take steps to meet the family planning needs of their populations as soon as possible and should, in all cases by the year 2015, seek to provide universal access to a full range of safe and reliable family planning methods and to related reproductive health services which are not against the law.” (UN, 1995, par. 7.16) With this emphatic statement, 179 governments expressed their commitment to the Programme of Action (PoA) at the International Conference on Population and Development (ICPD) held in Cairo, 1994. Targets were also set for funding the costs of implementing the PoA, with donor governments promising to finance one-third of the total amount of resource flows needed for population activities in developing countries. The ICPD PoA was lauded with praise and depicted as "a turning point in humanity” and "a quantum leap to a higher state of energy” (McIntosh and Finkle 1995).

Today, the program is near its end date and commentators, policy makers and advocates are worried by the unbalanced attention given to specific population issues within the ICPD agenda, and by the gap between the actual disbursements of funds and those that were promised. Specifically, many within the family planning movement are concerned by the dominance of STDs/HIV/AIDS programs ${ }^{1}$ and the comparative neglect of family planning and other aspects of reproductive health care in the Millennium Development Goals (MDGs) (cf. Cleland and Sinding, 2005). As Steven Sinding has stated: “If you're not an MDG, you're not on the agenda. If you're not a line item, you're out of the game” (cited in Crossette, 2005: 77).

Ever since its approval, the PoA has been plagued by many of the same kinds of problems that bedevil international development aid, aptly depicted by William Easterly in his book 'The White Man’s Burden’ (2006). In designing and executing the grand plans of bringing welfare and development to poorer countries, the only thing which seems to count is the movement of money. In the social engineering mindset of planners, the money should flow to places where the reproductive health status of women is

\footnotetext{
${ }^{1}$ The ICPD PoA frames all funding in for this category under the heading of Sexually Transmitted Diseases (STDs) including HIV/AIDS. Throughout the text we will use the shorter term HIV/AIDS and wherever UN figures are presented on HIV/AIDS, these also include STDs.
} 
threatened and family planning needs cannot be met due to a lack of resources. In this chapter, we will take up the question of how the funding efforts to achieve the ICPD's goals have fared since 1994, and what lessons can be learned from this experience so far.

\section{Tracking the good intentions of donors}

Compromises have to be drawn at population conferences, whose overall good intentions are often stated in such high spirits that some disappointment is inevitable in the years that follow, when attempts are made to put the grand ambitions of conference negotiations into practice. To understand the PoA, one first needs to consider the diverging views on population policies and the different schools of thought that surfaced at the Cairo conference (Potts, 2004). These ranged from groups traditionally opposed to organized family planning programs such as the Vatican, which continued its hard-line stand against any form of 'artificial contraception' and condemned the use of condoms; to those who had launched national family planning programs in many developing countries during the 1960s and thereafter, and who continued to maintain their concern about rapid population growth and emphasized that fertility would fall rapidly if only the unmet need for family planning was met in a respectful way. Other groups were also present at Cairo. They included the women's health advocates who focused on the needs of the individual woman and downplayed demographic forces, often portraying family planning programs as coercive; as well as groups emphasizing the inequalities between the global North and South and the need to redistribute the world's wealth more equally. Given such diverse views on population policies, the ICPD achieved a remarkable degree of consensus. Its PoA underscored the heavy burden of social and cultural injustice that falls on many women in the world. The conference considered sexually transmitted diseases (STDs) and HIV/AIDS, condemned female genital mutilation, and set family planning in a broad context of reproductive health care.

But how has the PoA fared in the terms that matter most for the citizens receiving the aid? It is almost impossible to review the entire field of reproductive health and the progress that has been made. Instead, we focus on the three most important elements of reproductive health and, specifically, discuss developments in: (1) family planning, which is key to increasing household wealth and to improving overall reproductive 
health; (2) maternal health, which is central to the health of women during pregnancy, childbirth and the postpartum period; and (3) HIV/AIDS, which destroys not only the human capital of those infected but also, as a potent infectious disease, involves a host of global public governance and program design problems in the provision of a global public good that entails more sophistication than top-down development planners seem ready to admit (Sandler, 2004).

In general, contraceptive use has increased over time, even in sub-Saharan Africa (SSA), and yet despite the considerable progress made during the 1990s in particular, services are still finding it hard to reach the poorest families. Table 1 presents some data from the Demographic Health Survey (DHS) program on how the demand for modern contraceptives across families of different wealth statuses is satisfied in the various regions of the world. In most countries the wealthiest 20 percent (Q5 in Table 1) of families are using family planning when they want no more children or want to space children at least 2 years apart. More recent evidence (Bernstein, 2006) shows that the progress continues, but the poorest families (Q1) in Sub-Saharan Africa still lag behind and less than a third of the poorest families can satisfy their demand for family planning.

\section{HERE TABLE 1}

The importance of this failure to access family planning in this part of the world becomes evident by taking account of the robust evidence on the relationship between contraceptive use and fertility Experience shows that as contraceptive prevalence rises, so the total fertility rate falls. A host of studies has documented the spread of fertility decline throughout the developing world, including SSA. Recently, however, concerns have emerged that the ongoing fertility decline has stalled in a number of African countries. For example, Ezeh et al. (2009) examined the stalling fertility transitions in four Eastern African countries (Kenya, Tanzania, Uganda and Zimbabwe) over two decades. They found that fertility decline has been highly selective among specific subgroups of women, especially the most educated and urban, whereas the fertility rate actually rose for women with little or no formal education. Acceptance of family planning as a legitimate way of controlling births may have even fallen; the proportion of 
Kenyan youth (15-19 years) who disapproved of family planning increased between 1998 and 2003 from 13 to 22 percent (Ezeh et al. 2009, p. 3005).

Maternal health is the second major element of reproductive health that we shall consider. Although motherhood is widely seen as a positive and fulfilling experience, for too many women in developing countries, it is also associated with suffering, ill-health and even death. In May 2008, WHO’s Executive Director acknowledged that progress had stalled towards reaching the MDGs, particularly MDG 5 (improving maternal health), and that continued progress would be "slow and uneven". Beyond the major direct causes of maternal morbidity and mortality (hemorrhage, infection, high blood pressure, unsafe abortion, and obstructed labor) maternal health may also be compromised by harmful behaviors. In Africa these include female genital mutilation. The most recent prevalence data indicate that 91.5 million African girls and women above 9 years old are currently living with the consequences of female genital mutilation (Yoder and Khan, 2008); and according to a consortium of health agencies, 100 to 140 million girls and women worldwide have undergone female genital mutilation/cutting, with more than 3 million girls at risk for cutting each year in Africa alone (WHO, 2008). The measurement and monitoring of maternal health are difficult, but we know that the divergence in maternal mortality rates throughout the world is very large. Although the most recent estimates indicated an overall decline in maternal deaths, the lifetime risk of dying from pregnancy and childbirth ranges from 1 in 4300 in developed countries, to as high as 1 in 31 in SSA (Hogan et al., 2010). Many more women are estimated to suffer pregnancy-related illnesses (9.5 million), near-miss events (1.4 million), and other potentially devastating consequences after birth (20 million longterm disabilities) (Fillippi et al., 2006). Access to antenatal and delivery care received varies widely. Also, about 19 million unsafe abortions are practiced annually worldwide and were estimated to account for 68,000 (or 13 percent of all) maternal deaths in 2000. The prevalence of unsafe abortion differs across regions and is higher in South America, many areas of SSA, and South Asia. Progress, however, is slow to achieve. Although some progress occurred in Latin American and the Caribbean over the period 1990-2000, most developing countries saw no appreciable change in their rates of unsafe abortion (Grimes et al., 2006). 
Finally, HIV/AIDS is the element of reproductive health which has received most attention over the period discussed. For 2009 it was estimated that 31-35 million people globally were living with HIV, 2.6 million people were newly infected (down from a peak of 3.2 million in 1997) and approximately 1.8 million people died from AIDSrelated causes (down from a peak of 2.1 million in 2004) (UNAIDS 2010). The prevalence rate varies greatly, from $0.1 \%$ among adults aged 15-49 years in East Asia to $5 \%$ in SSA, which continues to be the region most affected by the pandemic. It is still hard to speak of major progress in this field, but it is encouraging that the global AIDS pandemic appears to have stabilized. However, levels of new infections remain high and the number of people living with HIV worldwide has increased given the progress made in reducing mortality rates among those infected.

\section{Whatever happened to Cairo's good intentions?}

The ICPD's participants set themselves an ultimatum (the year 2015) for achieving the goals they had agreed upon in Cairo. Much has happened between 1994 and 2010, but it does not take an expert's eye to see that the ambitions of 1994 have not been realized and will probably also not be realized by the year 2015. The developed nations are trying to cope with the huge financial problems that have resulted in the aftermath of the 20082009 economic crisis; and given that population assistance is highly elastic with respect to income developments within donor countries (cf. Van Dalen, 2008), the financing of reproductive health aid is bound to be affected negatively. It is timely, therefore, to take stock of what may underlie the gap between intentions and actions. To unravel the reasons for the divergence between Cairo's ambitions and the day-to-day practice in matters of reproductive health, it may help to look at a number of different causes, ranging from the probable and simple to the more complex causes of development failure.

\subsection{No sense of urgency}

The first and most plausible reason goes to the heart of the issue of population assistance. Although women's reproductive rights figure prominently in the ICPD agenda, in the minds of decision makers, the concerns of economic growth, sound fiscal policy, and the 
miracle of making markets work, all outrank the more abstract issues of reproductive rights or reproductive health when thinking about development. As Peter Piot, the former head of UNAIDS, has once said: "I asked myself what political leaders really care about. The truth is, it's not health. It's economics and security. Health is what they talk about if there's money left at the end of the day.” For a long time, the Washington Consensus (Williamson, 1990) formed the dominant frame of mind, certainly during the $1990 \mathrm{~s}^{2}$.

It is understandable that economic policy makers are enchanted by an agenda formulated in economic terms. It may be somewhat puzzling, however, that demographic experts are less convinced about the case for population policies, including family planning programs, or about the oft-cited need to bring global population growth in line with the carrying capacity of the earth. In 2009, demographers of the International Union for the Scientific Study of Population (IUSSP) were asked a range of questions (Van Dalen and Henkens, 2011). ${ }^{3}$ Table 2 shows their spread of opinions about the sense of urgency (or the lack thereof) they ascribed to the Malthusian concern with population growth outpacing the carrying capacity of the earth. Approximately half of the demographers did not agree with the statement: "The current size of the world population exceeds the carrying capacity of the earth.”

\section{HERE TABLE 2}

This agnostic attitude is not without its consequences. We also tried to capture the attitude towards government intervention in reducing above replacement-level fertility rates and their preference of world population growth. By and large one can say that those who firmly disagree that the world population exceeds the carrying capacity of the earth are far more set on a laissez faire population policy (28 percent would never interfere in countries facing above replacement fertility), and they are also the ones who

\footnotetext{
2 The term "Washington Consensus" was first coined by John Williamson to describe the policy prescriptions promoted for crisis-ridden developing countries by Washington, D.C.-based institutions like the IMF, World Bank, and the US Treasury Department. It refers more generally to an orientation towards free market policies followed by both advanced and emerging economies. This mindset dominated economic thinking and the views of many politicians and journalists during the 1990s, but then ended with the outbreak of the 2008-09 financial crisis.

${ }^{3}$ The response rate was relatively high for such an expert survey (40\%) and included demographers from all corners of the world.
} 
want the world population to grow. The converse relationship applies to those who firmly agree with this Malthusian statement: virtually all of this group is in favor of government intervention and 76 percent wants a smaller world population. In short, if the low level of consensus on this particular issue among experts is also present among policy makers one can better understand why the sense of urgency is not all that strong and why achieving a consensus at global population conferences is such a difficult matter.

The demographers were also asked for their perceptions of the likelihood that the overall MDG goal of poverty reduction by half would be achieved by the year 2015. Over 70 percent did not believe that this goal would be achieved. Overambitious goals may be part of the rhetoric of conferences on development and foreign assistance, but the credibility of global collective action plans leaves much to be desired among experts.

\subsection{Insufficient funding}

A second and related reason for not achieving the goals of the ICPD is often aired by UNFPA and NGOs involved in matters of family planning and reproductive health: the funds to finance the PoA are insufficient. The latest evaluation of financial resource flows assisting the PoA was conducted in 2009; it noted that the ICPD target for donor countries was met in 2005 (UN, 2009). This achievement was unforeseen, not least because development aid generally does not meet promises. Indeed, it may even have caused some concern at the head offices of the UN, NGOs and government bureaus dealing with foreign aid for reproductive health, because continued flows for any development assistance project may partly depend on an ability to show that there is a gap between what is needed and what is available. For a long time, such gaps were visible and real in the case of reproductive health care (Potts et al., 1999). However, while the ICPD PoA may have seemed a logical contract from the layman's point of view, for the accountant who has to keep track of the good intentions, the financial paragraphs made for a nightmare. They included different commitments; targets for donors were set in real terms with nothing said about which deflator should be used (consumer price, the price of health care); targets for developing countries were stated in nominal terms; out-of-pocket expenditures for reproductive health care were delegated to an appendix; and the distribution across reproductive health categories remains arbitrary, 
perhaps because the dividing lines between those categories are in practice not as clear as they were in the heads of the conference delegates.

\section{HERE FIGURE 1}

If one takes a longer term perspective on population assistance (see Figure 1), the Cairo conference appears as a turning point in the short history of collective action on population issues. In nominal terms, funds have increased by a factor of ten since 1994 and in real terms, the increase, by a factor of 7.4, is less pronounced but still considerable. This increase may be explained by a number of plausible factors. Both the number of donors - not only governments but also private donors like the Bill and Melinda Gates Foundation - and the ‘wealth’ of donors have increased. However, two additional reasons may help explain why the achievement of the original PoA is to some extent illusory. We will discuss these under the headings of shifting priorities and diverging priorities over time.

\subsubsection{Shifting priorities}

Certain developments were unforeseen in the design of the PoA. The clearest example is, of course, the steep increase in HIV/AIDS prevalence. The enormous increases in funds allocated to HIV/AIDS programs obscures the fact that funds for other components of reproductive health are far below target and, in the case of family planning, have declined over time. The category of HIV/AIDS was allotted 7 percent of the funds allocated to all ICPD categories at the start of the PoA in 1994, a proportion that grew to as much as 74 percent in 2008 (see Figure 2). This shift in emphasis has been so strong that the funds allotted to non-HIV/AIDS categories has remained more or less the same since 1994 (see again Figure 1). ${ }^{4}$

\footnotetext{
${ }^{4}$ The share of general contributions in total development assistance for reproductive health (DARH) also decreased. This is somewhat surprising in view of the current debates among donors emphasizing the importance of funds that are not linked to specific projects or diseases. Advocacy of the new agenda for aid effectiveness embodied in the 2005 Paris Declaration and its follow-up, the Accra Agenda for Action, reflects a view that provision of unrestricted funds is the best funding method for alignment with the
} 


\section{HERE FIGURE 2}

Two factors have been pivotal in causing this shift in priorities. The first and more downto-earth observation is that at the time they made their pledges, the ICPD participants obviously did not realize how strong the spread of the HIV/AIDS epidemic would become, especially in SSA. The story of HIV/AIDS is, however, not only one about an infectious disease; it is also about technological progress, which has lengthened the remaining life expectancy of those infected. These two elements resulted in a strong increase in the number of people living with HIV/AIDS. Global awareness of the HIV/AIDS pandemic mounted steadily and was expressed in the UN Millennium Declaration adopted in September 2000. Nevertheless, the huge increase in funds that became available to fight the rapidly spreading pandemic should be primarily ascribed to the initiative of U.S. President George W. Bush, who started in 2003 what became known as the PEPFAR program (US President's Emergency Plan for AIDS Relief). ${ }^{5}$

This global collective action was underpinned by the second factor that explains the strong increase in funds: the emergence of the MDGs. Besides halving the proportion of the world's people whose income is less than one dollar a day by the year 2015, the MDGs also sought to reduce by the same date under-five child mortality by two-thirds (MDG 4) and maternal mortality by three-quarters (MDG 5); and to halt, and begin to reverse, the spread of HIV/AIDS and the scourge of malaria and other major diseases (especially tuberculosis) (MDG 6). Although highly complementary to the ICPD’s PoA, this new UN initiative was also, to some extent, competing with it. ${ }^{6}$

The ICPD PoA urged the international community to take steps towards ensuring universal access to reproductive health services. The ICPD agenda for reproductive

priorities of recipient countries and improved harmonization among donors. As a result, donors have pledged to move away from project-related aid in favor of general and sector budget support. Clearly, this has not happened in the domain of DARH.

${ }^{5}$ The remarkable increase of funds allocated to STDs/HIV/AIDS between the years 2004 and 2005 is due to the implementation of PEPFAR, which holds a place in history as the largest effort by any nation to combat a single disease.

${ }^{6}$ In his address to the $5^{\text {th }}$ Asian and Pacific Population Conference in 2002, the former Secretary-General of the UN, Mr. Kofi Annan, made the following remark: "The MDGs, particularly the eradication of extreme poverty and hunger, cannot be achieved if questions of population and reproductive health are not squarely addressed" (UNFPA, 2004). 
health has been considered its most comprehensive element, broadening the spectrum of reproductive health services and influencing many countries to embark upon initiatives to improve the reproductive health status of their populations. However, with the ratification of the MDGs, the focus of most countries shifted from concepts highlighted by the ICPD towards achieving the MDGs. Presently, the term 'ICPD' is hardly mentioned anymore and all categories are interpreted within the 'MDGs.' To be sure, although there is not a direct convergence between the ICPD's PoA and the MDGs, there is a significant overlap, especially with regard to MDGs 5 and 6. Nevertheless, the health-related MDGs are less comprehensive than the ICPD categories: they do not include family planning or related program elements such as information, education and communication campaigns, and other health programs. Moreover, as the MDGs have become increasingly important for setting donor priorities, the fact that family planning does not feature as one such distinct MDG goal would put at risk efforts aimed at securing enough funding for improving this category.

\subsubsection{Diverging priorities}

Shifting priorities may not trouble the 'madmen in authority' as long as the course set is right and that there exists a consensus on the direction and intensity of the shift. However, another distinguishing mark of global collective action and reproductive health in particular is that priorities may shift in unpredictable ways. In general, three reasons can be put forward why priorities may shift in making donations. These include diverging preferences and ideologies, a growing inability to pay, and the problem of 'free riders,' as discussed below.

\section{Diverging preferences and ideologies}

The provision of funds is a matter of 'taste': a taste for caring about others, or a preference for certain programs which are in line with one's religious beliefs or Weltanschauung. In this respect, one can expect some donor countries to be more sensitive than others towards the fate of people living in the less developed world when (population) programs are more in line with their preferences or political ideology; or because of geographic proximity or historical ties such as to former colonies (Alesina and 
Dollar, 2000). Furthermore, governments of, for example, Scandinavian countries and the Netherlands are known to be more egalitarian than Anglo-Saxon countries in their national economic policies, and such preferences tend to carry over towards attempts to reduce income differences in the world at large. But differences in taste may also be reflected in religious and other belief systems and such differences may surface at distinct points in time. For instance, diverging views on the importance of reproductive health were a hurdle of some significance in the adoption of the MDGs. Due to the increased concern with mass poverty in the 1990s, the international community adopted the international development goals (IDGs), one of which focused exclusively on providing access to reproductive health for all women of appropriate age. ${ }^{7}$ With the transformation of IDGs to MDGs at the UN Millennium Development Summit in 2001, the reproductive health goal was dropped from the agenda, mostly because of opposition from conservative developing nations and North American right-wing groups (Crossette, 2005; Campbell-White et al., 2006). However, after lobbying by many governments, NGOs and others, world leaders endorsed incorporating universal access to reproductive health as a target within MDG 5 (improving maternal health).

Perhaps the most significant policy which illustrates the diverging views on family planning refers to the U.S. government's so-called 'Mexico City Policy,' first introduced by President Reagan in 1984 and re-imposed by successive Republican Party presidents. This ruling, dubbed by its opponents 'the Global Gag Rule,' restricted foreign NGOs that received USAID family planning funds from using their own, non-USAID funds to provide any abortion-related activities. The policy was rescinded by President Clinton in 1993, reintroduced by President George W. Bush, and rescinded again by President Obama in 2009. It is not surprising that ideology matters in making choices, but what made this U.S. foreign aid policy different from other textbook public choices is that it may have had substantial spillovers in the decisions and actions of other donor countries and aid recipients, and at some points it may even have affected researchers'

\footnotetext{
${ }^{7}$ For further information see, for example, the description given in the Asian Development Bank's donor report on "Fighting Poverty in Asia," available at: http://www.adb.org/Documents/Reports/ADF/VIII/adf0200.asp
} 
freedom of speech. ${ }^{8}$ Even though it is extremely difficult to gauge the actual effects of the policy, it likely increased the number of abortions where the US government's imposed restrictions disrupted the provision of family planning activities (Crane and Dusenberry, 2004).

\section{HERE FIGURE 3}

Dominance is seldom healthy, be it in private or public affairs. The recent Global Gag Rule is a powerful reminder of the overpowering dominance of the United States and the ideological values held by many Republicans in setting the rules of the game in global health programs (Kulczycki, 2007; Crimms, 2007; Van Dalen, 2008). Perhaps this is most clearly illustrated by the erratic funding pattern received from USAID over the past four decades by UNFPA, the key player charged with keeping track of the ICPD agenda (Figure 3). This leads to potentially far-reaching consequences. In short, U.S. dominance disrupts the global public governance of the reproductive aid process.

\section{Lack of ability to pay}

Donor governments themselves often make this argument when funds are not forthcoming and the press or a consortium complains about members not living up to their promises. Foreign aid is part of the budget deliberations of national governments, and when a business cycle downturn occurs or when other unexpected demands on government spending emerge, ambitions have to be toned down and priorities changed. The emergence of the credit crunch in 2008 made it inevitable that donor governments would reappraise their priorities and slash official development assistance. The income elasticity of government donations with respect to reproductive health is unity (Van Dalen and Reuser, 2006), implying that a fall in national income by 10 percent implies more or less an equal fall in reproductive health aid.

\footnotetext{
${ }^{8}$ International Perspectives on Sexual and Reproductive Health (formerly known as International Family Planning Perspectives), one of the most influential peer-reviewed journals on reproductive health, inserted from 2002 to March 2008 the following restriction in its guidelines to authors: "Because the journal receives funding from the US Agency for International Development, it is prohibited under the Helms amendment (P.L. 93-189) from publishing material that promotes abortion.” As with all scientific research, however, it remains an open question whether the publishing policy guideline affected actual decisions implemented.
} 


\section{3. 'Free rider' behavior in financing global public goods.}

The ideal world of social planners is destroyed by free riders. This includes individual governments who benefit from collective action but who do not contribute, or who do not contribute sufficiently, such that goods are either not provided or in inadequate amounts. Reproductive health aid poses a collective action problem for the international community not unlike many other foreign aid programs. Many developing nations must rely on other nations to provide them with resources and cash to finance population activities like family planning, investments in reproductive health, HIV/AIDS programs and basic research. By increasing the welfare of a recipient country, foreign aid serves as a collective global good for all donor countries. The U.S. government has been the largest donor of public development assistance for reproductive health (DARH) throughout this time, accounting on average for 40 percent of the total amount of DARH. Following its entry into the DARH arena in 1998, the Bill \& Melinda Gates Foundation became the largest private donor, but the continued dominance of the U.S. government's contribution to the DARH has allowed the US government to push its own priorities in global health programs (Van Dalen, 2008). Dominant parties have the unattractive feature of not only dominating the agenda, but also encouraging free riding by smaller countries. The reproductive health agenda is a case in point. This mechanism is akin to a host of collective action failures in foreign aid and may well explain why promises are rarely met. Detecting free rider behavior is, however, far more difficult than stating the problem of free riders. Van Dalen (2008) has shown that free riding is not present for each and every category.

\subsection{Misalignment of donor funds}

A final reason why the good intentions have not fully realized pertains to a misalignment between needs and funds. In an analysis using multiple waves of data from 41 Demographic Health Surveys (DHS) conducted between1988-2006, Case and Paxson (2009) document how strong the impact of the HIV/AIDS pandemic has been on nonAIDS related health services. They found a clear deterioration in the quality of care received by women and children as measured by indicators of antenatal care, birth 
deliveries and children's immunization in this specific period. The real root of this problem cannot be detected using DHS data, but Case and Paxson show that this divergence in quality of non-HIV related services between low and high prevalence HIV regions started in the mid-1990s. Ideally one would expect governments to donate and allocate resources efficiently so as to achieve the 'biggest bang for the buck', or to rephrase this in the language of the 2004 Global Forum for Health Research: health research and development priorities should be set according to, among other factors, reduction in the burden of disease per dollar spent. As funding for HIV/AIDS has come to dominate the ICPD agenda, it is natural to ask whether this dominance could be justified by the concern of donor countries about the needs of developing countries. One way to answer this question is to link donor funding to the burden of disease in developing countries, as measured by disability adjusted life-years (DALYs). ${ }^{9}$

If it is assumed that donors respond in proportion to the scale of health problems in the developing world, one would expect a certain level of correspondence between donor funding for a health category (e.g. HIV/AIDS) and the corresponding burden of disease. At a rudimentary level, this link can be established using data on DALYs from the Global Burden of Disease (GBD) project, ${ }^{10}$, so that funding levels for the project's disease categories should be directly comparable to two of the four ICPD-costed population package categories: (1) STDs, including HIV/AIDS; and (2) reproductive health diseases, mainly maternal and perinatal conditions. ${ }^{11}$

As can be distilled from Table 3, donor dollars spent per healthy life-year lost differ significantly between these two ICPD categories. This indicates that by this criterion, the principles of efficiency are not obeyed. In the late-1990s, the category 'reproductive health' received more funding per DALY relative to HIV/AIDS. This situation was reversed in the following decade: the category HIV/AIDS was heavily favored relative to

\footnotetext{
${ }^{9}$ Researchers developed the DALY measure explicitly in recognition of resource scarcity to aid policymakers in making difficult allocation decisions (World Bank, 1993; Murray and Lopez, 1996).

${ }^{10}$ The data are available for the following years: 1990, 1998, 1999, 2000, 2001, 2002, and 2004 (World Bank, 1993; WHO, various years).

${ }^{11}$ We have also included reproductive cancers in this category. These account for a negligible share both in the total burden of disease due to reproductive conditions and in the donor funding (a detailed project description search revealed only a handful of projects targeted at reproductive cancers). However, it should be realized that reproductive cancers in developing countries are significantly underreported. Excluding this category from our calculations does not change the results.
} 
the burden it caused, receiving US\$76 per DALY relative to only US\$18 per DALY received by reproductive health. While funding per DALY due to HIV/AIDS increased more than tenfold between the late-1990s (1995-99) and c. 2004 (2000-07), funding per DALY due to maternal and perinatal conditions - disease categories that are of particular concern to vulnerable groups, namely women and infants - increased by only 89 percent. Altogether, this suggests that HIV/AIDS as a category received more donor funding than can be explained by its share in the burden of disease.

\section{HERE TABLE 3}

Table 3 highlights the prominence of HIV/AIDS on the donor agenda in the first years of the new century. Although other research has come to similar conclusions (UNFPA, 2004; Van Dalen and Reuser, 2006), the new results presented here additionally show that the increased funding for HIV/AIDS activities cannot be explained by its share in the burden of disease. Reproductive health problems have received relatively less funding, although they pose a significant burden in terms of DALYs in developing countries.

Ethiopia is a typical example of how the foreign aid priorities of donor nations are not always aligned with local health needs. A large portion of foreign aid to Ethiopia goes towards HIV/AIDS even though its national prevalence rate is relatively low (2.3\%) and its Ethiopia's maternal mortality rate is among the highest in the world. The biggest needs of the Ethiopian population, which is largely rural, include safe water, transportation, and more doctors, nurses, and midwives (Loewenberg, 2010). Yet all of these basics receive little attention from foreign donors. Given the lack of health insurance, Ethiopians pay a large share of their health expenditures - including expenditures for reproductive health - out of their own pocket. Although maternal health services delivered at public facilities are free in principle, about half of the mothers delivering at public hospitals reported making out-of-pocket expenditures to get needed healthcare services (Micevska Scharf, 2010). The highest amounts were spent on drugs and medical supplies, with transport, accommodation, food, and other indirect expenses also accounting for a large fraction of out-of-pocket expenditures by mothers giving birth. Overall, the combined direct and indirect cost of the supposedly 'free' maternity 
care services is significant in Ethiopia and may deter utilization of health services, especially by poor mothers.

The global burden of disease is increasingly shifting from infectious diseases to non-communicable diseases. As a result, WHO predicts that mortality due to maternal and perinatal conditions in developing countries may feature even more prominently in the global picture of health over the next 20 years (WHO, 2008). These predictions are debatable for various reasons, for example, some maternal and perinatal conditions are due to HIV/AIDS, and there may be more progress made than anticipated to combat maternal and perinatal conditions. Nevertheless, if funding for family planning and reproductive health is not increased, it will undermine efforts to prevent unintended pregnancies, and reduce maternal and infant mortality in the years to come.

\section{Lessons from inside and outside the money machine}

If the participants of the ICPD would meet again in 2015, would they do things differently? What lessons would they draw from 20 years of development experience? These type of questions will certainly have to be faced when the final date of 2015 approaches. In this closing section we will draw together a number of lessons that emerge from the history of development so far.

The first lesson is that a strong focus on monetary targets -- as set in 1994 at Cairo -- is impractical: resource tracking has proven to be extremely difficult. To be sure, the transparency of donor organizations and recipient governments should be a guiding principle for their day-to-day operations; and given the frequently disappointing results of foreign direct assistance, it would be enlightening to examine the day-to-day practice of development aid, and simply 'follow the money' and see how funds are spent in countries of destination. Furthermore, observers of development aid should guard against oversimplifying the complexity of reproductive health aid, household behavior and welfare; viewing them as simply regressions may give policy makers the illusion that such policies have large social external benefits, whereas closer examination of the richness of the relationships between fertility and human capital formation within households shows far smaller effects of policies on family outcomes (Schultz, 2008). The provision of reproductive health aid should be guided by more than the maxim 'it is the thought that 
counts'. Nevertheless, the quality of data on the type of health expenditures that recipient governments spend is both weak and incomplete, and the lack of reliable data gives significant leeway for various agencies and pressure groups to claim more and more resources for their goals. In this line of development work, it is often hard to distinguish between the words of an independent scholar and that of a compassionate policy advocate. For health policies to work best, it may be best to formulate goals in the terms that matter most, that is, the health outcomes and demographic indicators which capture the essence of the intentions of participants. The MDGs go a long way in capturing the essence of reproductive health aid, but they have the drawback that essential services that complement efforts to reduce the spread of HIV/AIDS have been left out.

A second lesson concerns the need for more attention to be paid to incentives and the benefits of social insurance. Overall, citizens in developing countries pay a large share of their health expenditures out of their own pocket. Access to health care is intimately tied to the resources and incentives in health insurance and production. ${ }^{12}$

A third lesson, which is related to the previous two, concerns the need for a comprehensive approach to the evaluation of reproductive health policy (Van Dalen and Reuser, 2008). The apparent success of fertility decline seems to have made many policy advisers and advocates over-confident that fertility levels and maternal health are no longer a problem. They have shifted their focus almost exclusively to HIV/AIDS, which received only $7 \%$ of funding at the time of the 1994 Cairo pact. With the benefit of hindsight, the various categories of allocation (basic research, family planning, reproductive health and HIV/AIDS) used by the PoA quickly became outdated. A major factor that led donors to reconsider their priorities was the course of the HIV/AIDS pandemic. This seemed to rapidly escalate and required more attention than was envisioned in Cairo. Also, the ICPD’s budgetary targets were set too low to significantly advance goals such as to "provide universal access to a full range of safe and reliable family planning methods.” According to ICPD projections at the time, reproductive health costs in developing countries and countries in transition would likely total 17 billion US dollars in the year 2000 and 21.7 billion US dollars in 2015 (at 1993 US

\footnotetext{
${ }^{12}$ The faltering experiment in the provision and insurance of health care in China (WHO, 2005, Meng et al., 2000, Liu et al, 2000) may provide ample evidence of outright market failure and highlights that government should play a pivotal role in setting up a basic form of health insurance.
} 
dollars). ${ }^{13}$ The latest revision of the total package that is needed to fulfill the dreams of Cairo amounted to 64.7 billion in 2010, a sum expected to reach 69.8 billion US dollars in 2015 (UNFPA, 2009).

There are two main reasons why the crowding out of family planning and maternal health investments in favour of HIV/AIDS assistance is worrisome. First, HIV/AIDS programs would profit considerably from a more balanced approach, as maternal health and family planning investments go to the heart of the problems of SSA in particular, that high population growth rates keep numerous countries trapped in poverty (Cleland and Sinding, 2005). In most SSA countries, the TFR hovers around five, far above the replacement rate of 2.1 children. Judging from the DHS surveys carried out in developing countries, desired fertility rates fell faster over time than actual rates, as reflected in high levels of unmet need and high proportions of births that are ill-timed or unwanted. High fertility leads to rapid population growth rates, exacerbating scarcities in health care, education, land for farmers, and all other public domains of life. Family planning might alleviate some of these problems, but evidently it is no longer the "hot" subject it was for such a long time at many a population conference. Insiders to these negotiations claim that family planning seems even to have become "morally suspect" again (Blanc and Tsui, 2005). This is particularly unfortunate because the evidence of progress in maternal health has been relatively weak and investment is very much needed. $^{14}$

Second, the unprecedented rise of HIV/AIDS funds is disrupting fiscal policy and local health care systems, whereas a more balanced investment in reproductive health and HIV/AIDS would make use of the existing infrastructure. Vertical programs such as HIV/AIDS erode primary health care systems in developing nations. The substantial new levels of HIV/AIDS funding are swamping public health budgets, in some cases exceeding 150 percent of the government's total allocation to health care (Lewis, 2005). Too much money must be spent in too short a time. Such a situation, particularly in the

\footnotetext{
${ }^{13}$ This clause was made explicit for donor countries in the ICPD PoA (par. 14.11), and it was once explicated for developing countries in one of the preparatory committees (UNFPA, 1994)

${ }^{14}$ It should be noted with respect to the latter shortcoming that a recent initiative launched by the Bill and Melinda Gates Foundation and others (at the Women Deliver conference, 2010) intends to invest much more money into efforts to reduce maternal mortality.
} 
conditions of extreme poverty and poor governance prevalent in SSA, easily results in the "poaching" of health care workers and bureaucrats from other worthy public projects. Large "white elephant" investment projects signal to donors that money is being spent (Robinson \& Torvik, 2005), but chances are that resources are not spent wisely. When public governance systems are weak, these large but volatile sums of "easy money" promote corruption, moonlighting, and absenteeism in delivering health care (World Bank, 2004).

The short history of reproductive health aid is not a story of grand successes: collective action is an intricate and delicate balancing act. Spending large aid budgets on HIV/AIDS is a delicate cocktail, and an unbalanced mixture may do more harm than donors imagine. Foreign aid ought to be guided not by ideas or ideologies that have lost touch with reality or that are used opportunistically, but by evidence and true engagement, aiming at long-term sustainable solutions.

\section{References:}

Alesina, A., \& Dollar, D. (2000). Who gives foreign aid to whom and why? Journal of Economic Growth, 5, 33-63.

Bernstein, S. (2006). The Impact of Population Growth on the Attainment of the Millennium Development Goals and other Consensus International Development Goals, New York: UNFPA.

Blanc, A., \& Tsui, A. (2005). The dilemma of past success: Insiders' view on the future of the international family planning movement. Studies in Family Planning; 36, 263-276.

Campbell-White A., Merrick, T.W. \& Yazbeck, S.A. (2006). Reproductive health: The missing millennium development goal. Washington DC: The World Bank.

Case, A., \& Paxson, C. (2009). The impact of the AIDS pandemic on health services in Africa: Evidence from Demographic and Health Surveys. Cambridge MA: NBER working paper, no. 15000.

Cleland, J., \& Sinding, S. (2005). What would Malthus say about AIDS in Africa? Lancet 366, 1899 - 1901. 
Crane, B.B., \& Dusenberry, J. (2004). Power and politics in international funding for reproductive health: The US Global Gag Rule. Reproductive Health Matters, 12(24), 128-137.

Crimms, N.J. (2007). The Global Gag Rule: Undermining national interests by doing unto foreign women and NGOs what cannot be done at home, Cornell International Law Journal, 40: 587-633.

Crossette B. (2005). Reproductive health and the Millennium Development Goals: The missing links. Studies in Family Planning 36, 71-79.

Easterly, W. (2006). The White Man's Burden: Why the West's Efforts to Aid the Rest Have Done So Much Ill and So Little Good. New York: The Penguin Press.

Ezeh, A.C., Mberu, B.U., \& Emina, J.O. (2009). Stall in fertility decline in Eastern African countries: Regional analysis of patterns, determinants and implications. Philosophical Transactions of the Royal Society, Biological Sciences, 364, 29913007.

Fillipi, V. et al. (2006). Maternal health in poor countries: the broader context and a call for action. Lancet. 368(9546), 1535-41.

Grimes, D.A., et al. (2006). Unsafe abortion: the preventable pandemic. Lancet 368 (9550), 1908-19.

Hogan MC, Foreman KJ, Naghavi M, Ahn SY, Wang M, Makela SM, Lopez AD, Lozano R, Murray CJ (2010). Maternal mortality for 181 countries, 1980-2008: A systematic analysis of progress towards Millennium Development Goal 5. Lancet 375(9726):1609-23

Kulczycki, A. Ethics, ideology, and reproductive health policy in the United States. Studies in Family Planning, 2007; 38(4): 333-351

Lewis, M. (2005). Addressing the challenges of HIV/AIDS: Macroeconomic, fiscal and institutional issues, Working Paper, no. 58, Helsinki: Center for Global Development.

Liu, X., Liu, Y. \& Chen, N. (2000). The Chinese experience of hospital price regulation. Health Policy and Planning 15: 157-163.

Loewenberg, S. (2010). Ethiopia struggles to make its voice heard. Lancet 376, 861-862. 
McIntosh, CA \& Finkle JL. (1995). The Cairo conference on population and development: A new paradigm? Population and Development Review, 21(2): 223260.

Meng, Q., Liu, X. \& Shi, J. (2000). Comparing the services and quality of private and public clinics in rural China. Health Policy and Planning 15: 349-356.

Micevska Scharf, M. (2010). Examining out-of-pocket expenditures on sexual and reproductive health in rural Ethiopia. Mimeo, The Hague: NIDI.

Murray, C.J.L. \& Lopez, A.D. (1996). The global burden of disease. Cambridge, MA: Harvard School of Public Health, World Health Organization and World Bank.

Population Action International (2010). Trends in U.S. Population Assistance. Washington DC: Population Action International.

Potts, M. (2004). Family planning programs: Development and outcomes. International Encyclopedia of the Social and Behavorial Sciences, 5332-5336. Amsterdam: Elsevier.

Potts, M., Walsh, J., McAninch, J., Mizoguchi, N. \& Wade, T.J. (1999). Paying for reproductive health care: What is needed, and what is available? International Family Planning Perspectives, 25, S10-S16.

Robinson, J.A. \& Torvik, R. (2005). White Elephants. Journal of Public Economics 89: $197-210$.

Ross, J., Stover, J., \& Adelaja, D. (2005). Profiles for family planning and reproductive health programs. 2nd edition, Glastonbury: Futures Group.

Sandler, T. (2004). Global collective action. Cambridge: Cambridge University Press.

Schultz, T.P. (2008). Population policies, fertility, women's human capital, and child quality. In: T.P. Schultz and J. Strauss (eds.), Handbook of development economics, vol. 4, chapter 52, Amsterdam: North-Holland.

UN (1995). Report of the International Conference on Population and Development. A/CONF.171/13/Rev.1. New York: United Nations.

UN (2009). Flow of financial resources for assisting in the implementation of the Programme of Action of the International Conference on Population and Development, Economic and Social Council, E/CN.9/2009/5. New York: United Nations. 
UNAIDS/WHO (2010) Report on the Global HIV/AIDS Epidemic 2010. Geneva: UNAIDS and WHO.

UNFPA (1994). Background note on the resource requirements for population programmes in the years 2000-2015, working paper prepared for the ICPD, New York: UN.

UNFPA (2004). Investing in people: national progress in implementing the ICPD programme of action 1994-2004. New York: United Nations.

UNFPA (2009). Revised cost estimates for the implementation of the Programme of Action of the International Conference on Population and Development: A methodological report, New York: United Nations.

UNFPA/NIDI (2010). Resource Flows Database, New York/The Hague.

Van Dalen, H.P. (2008). Designing global collective action in population and HIV/AIDS programs, 1983-2002: Has anything changed? World Development, 36(3), 362382.

Van Dalen, H.P. \& Henkens, K. (2011). What's on a Demographer's Mind? A WorldWide Survey, mimeo, The Hague: NIDI.

Van Dalen, H.P., \& Reuser, M. (2005). Assessing size and structure of worldwide funds for population and AIDS activities, NIDI report, The Hague: NIDI.

Van Dalen, H.P., \& Reuser, M. (2006). What drives donor funding in population assistance programs? Evidence from OECD countries. Studies in Family Planning 37, 141-154.

Van Dalen, H.P., \& Reuser, M. (2008). Aid and AIDS: a delicate cocktail, Vox Research-Based Policy Analysis and Commentary from Leading Economists, 0707-2008.

WHO (2005). China: Health, poverty and economic development. Beijing, WHO representative in China. http://www.who.int/macrohealth/action/CMH_China.pdf WHO (2008). World health statistics 2008. Geneva: World Health Organization.

WHO et al. (2008). Eliminating female genital mutilation - An interagency statement, Geneva: World Health Organization.

WHO/UNICEF/UNFPA/World Bank (2010) Trends in Maternal Mortality: 1990 to 2008 (Geneva: WHO). 
Williamson, J. (1990). What Washington means by policy reform. In J. Williamson (ed.), Latin American adjustment: How much has happened? Washington: Institute for International Economics.

World Bank (1993). World development report - Investing in health. Oxford: Oxford University Press.

World Bank (2004). World development report - Making services work for poor people. Oxford: Oxford University Press.

Yoder P.S. \& Khan S. (2008). Numbers of women circumcised in Africa: The production of a total. Calverton, MD: Macro International Inc. 
Table 1: Proportions of Demand for Family Planning Satisfied (in percentage terms) by Modern Contraceptive Use by Wealth Quintile (Q1 poorest, Q5 wealthiest), selected major world regions, 1990-2000

\begin{tabular}{|c|c|c|c|c|c|c|c|}
\hline & Period & Q1 & Q2 & Q3 & Q4 & Q5 & $\begin{array}{c}\text { All } \\
\text { quintiles }\end{array}$ \\
\hline \multirow{2}{*}{$\begin{array}{l}\text { Sub Saharan } \\
\text { Africa }\end{array}$} & 1990-1995 & 12.9 & 16.0 & 17.7 & 24.7 & 36.9 & 22.9 \\
\hline & 1996-2000 & 23.7 & 25.2 & 29.1 & 37.2 & 48.0 & 33.9 \\
\hline \multirow[t]{2}{*}{ Latin America } & 1990-1995 & 29.4 & 40.7 & 49.0 & 57.4 & 65.3 & 50.0 \\
\hline & 1996-2000 & 38.1 & 48.8 & 57.3 & 61.7 & 68.0 & 56.4 \\
\hline \multirow[t]{2}{*}{ Asia } & 1990-1995 & 48.2 & 51.0 & 57.5 & 57.5 & 67.6 & 57.1 \\
\hline & 1996-2000 & 50.0 & 57.1 & 59.8 & 63.7 & 70.7 & 60.9 \\
\hline \multirow{2}{*}{$\begin{array}{l}\text { North Africa/ } \\
\text { Middle East }\end{array}$} & 1990-1995 & 36.8 & 45.7 & 53.7 & 58.2 & 65.4 & 53.8 \\
\hline & 1996-2000 & 49.7 & 59.0 & 62.0 & 67.5 & 70.5 & 62.7 \\
\hline \multirow[t]{2}{*}{ Global average } & 1990-1995 & 29.2 & 35.8 & 40.4 & 46.2 & 55.6 & 42.7 \\
\hline & 1996-2000 & 37.9 & 44.4 & 49.3 & 54.7 & 62.1 & 50.8 \\
\hline
\end{tabular}

Source: Ross et al. (2005: 52). Regional averages are unweighted averages for countries within these regions. The original data are from the Demographic Health Survey program. 
Table 2: Atttitudes of demographers regarding whether theworld's population growth exceeds its carrying capacity and the likelihood of achieving the MDG poverty reduction goal (percentage agreement)

\begin{tabular}{|c|c|c|c|c|c|}
\hline Statement & $\begin{array}{l}\text { Fully } \\
\text { agree }\end{array}$ & agree & $\begin{array}{c}\text { Neither } \\
\text { agree/disagree }\end{array}$ & disagree & $\begin{array}{l}\text { Fully } \\
\text { disagree }\end{array}$ \\
\hline & \multicolumn{5}{|c|}{ Percentages } \\
\hline $\begin{array}{l}\text { "The current size of the world } \\
\text { population exceeds the carrying } \\
\text { capacity of the earth." }\end{array}$ & 12 & 22 & 17 & 32 & 17 \\
\hline $\begin{array}{l}\text { "The UN Millennium Development } \\
\text { Goal to reduce absolute poverty by } \\
\text { half for the world as a whole by the } \\
\text { year } 2015 \text { is an illusion.” }\end{array}$ & 31 & 40 & 10 & 14 & 5 \\
\hline
\end{tabular}

The survey was carried out among demographers of the International Union for the Scientific Study of Population (IUSSP) in 2009, $\mathrm{N}=$ 875. Source data: Van Dalen and Henkens (2011).

Table 3: Donor funding levels for STDs/HIV/AIDS and reproductive health diseases, c. 1998-2004

\begin{tabular}{|lcccccc|}
\hline & \multicolumn{2}{c}{$\begin{array}{c}\text { DALYs } \\
\text { (millions) }\end{array}$} & \multicolumn{2}{c}{$\begin{array}{c}\text { Donor funding } \\
\text { (millions of US\$) }\end{array}$} & \multicolumn{2}{c|}{$\begin{array}{c}\text { Donor dollars per } \\
\text { DALY }\end{array}$} \\
& late 1990s & $2000 s$ & late 1990s & $2000 s$ & late 1990s & 2000 s \\
\hline $\begin{array}{l}\text { STDs including } \\
\text { HIV/AIDS }\end{array}$ & 188 & 315 & 1,371 & 23,887 & 7.29 & 75.86 \\
\hline $\begin{array}{l}\text { Reproductive health } \\
\text { diseases }\end{array}$ & 209 & 435 & 2,042 & 8,023 & 9.78 & 18.46 \\
\hline
\end{tabular}

Notes: Donor funding for the late 1990s is a sum of funding levels in current US\$ over the years 1995-1999; donor funding for the 2000s is a sum of funding levels in current US\$ over the years 2000-2007. DALYs for the late 1990s are averaged over the years 1998 and 1999; DALYs for the 2000s are averaged over the years 2000, 2001, 2002, and 2004. Reproductive health diseases include maternal and perinatal conditions, and reproductive cancers. Sources: WHO (various years); UNFPA/NIDI Resource Flows Project Database. 
Figure 1: Development of primary funds for population assistance programs, 19732008 (million US dollars, nominal and at constant 1994 prices)

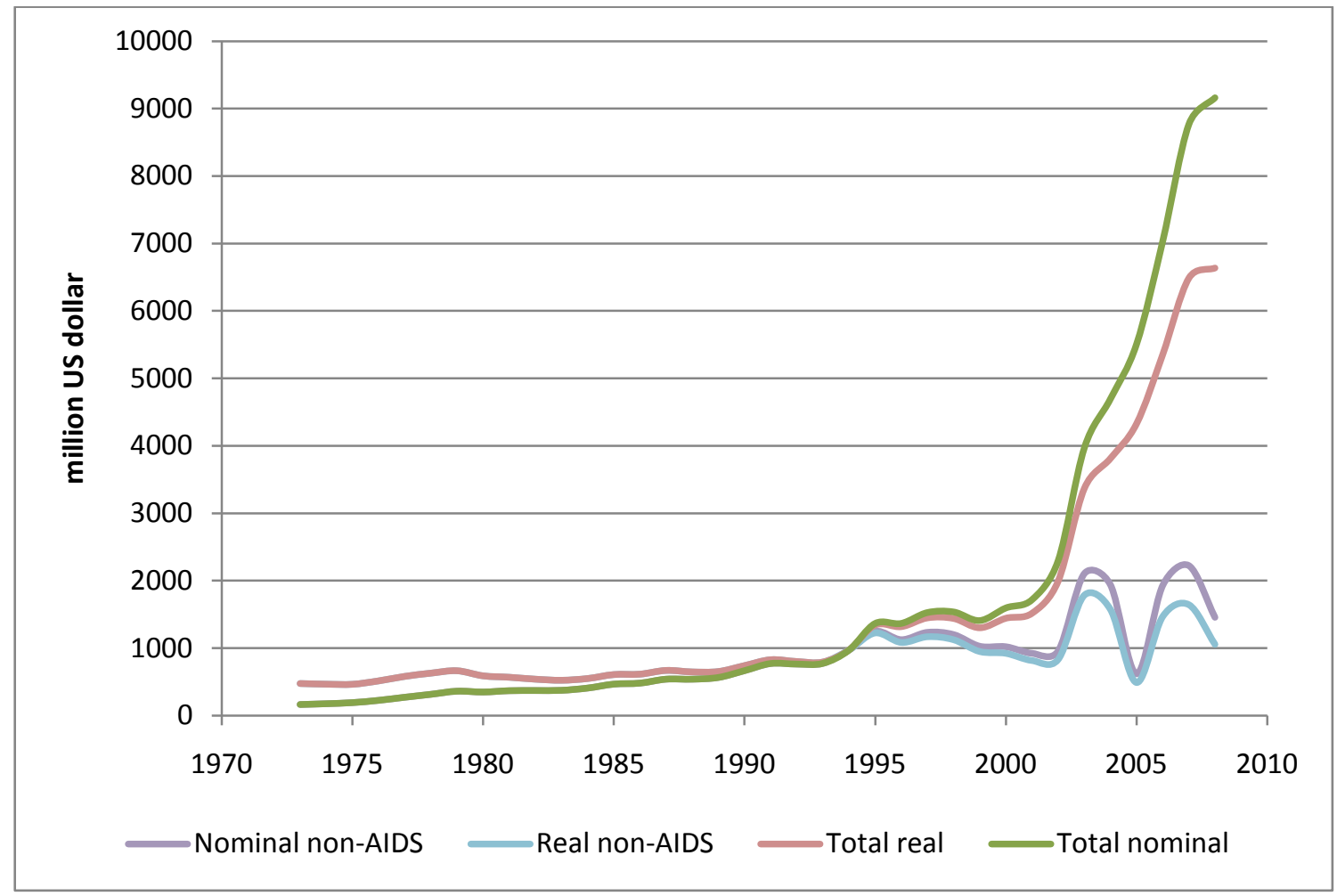

Source: Van Dalen and Reuser (2005) and UNFPA/NIDI database. 
Figure 2: Development assistance for reproductive health (DARH) from 1995 to 2008 by share of reproductive health category in total (excluding general contributions)

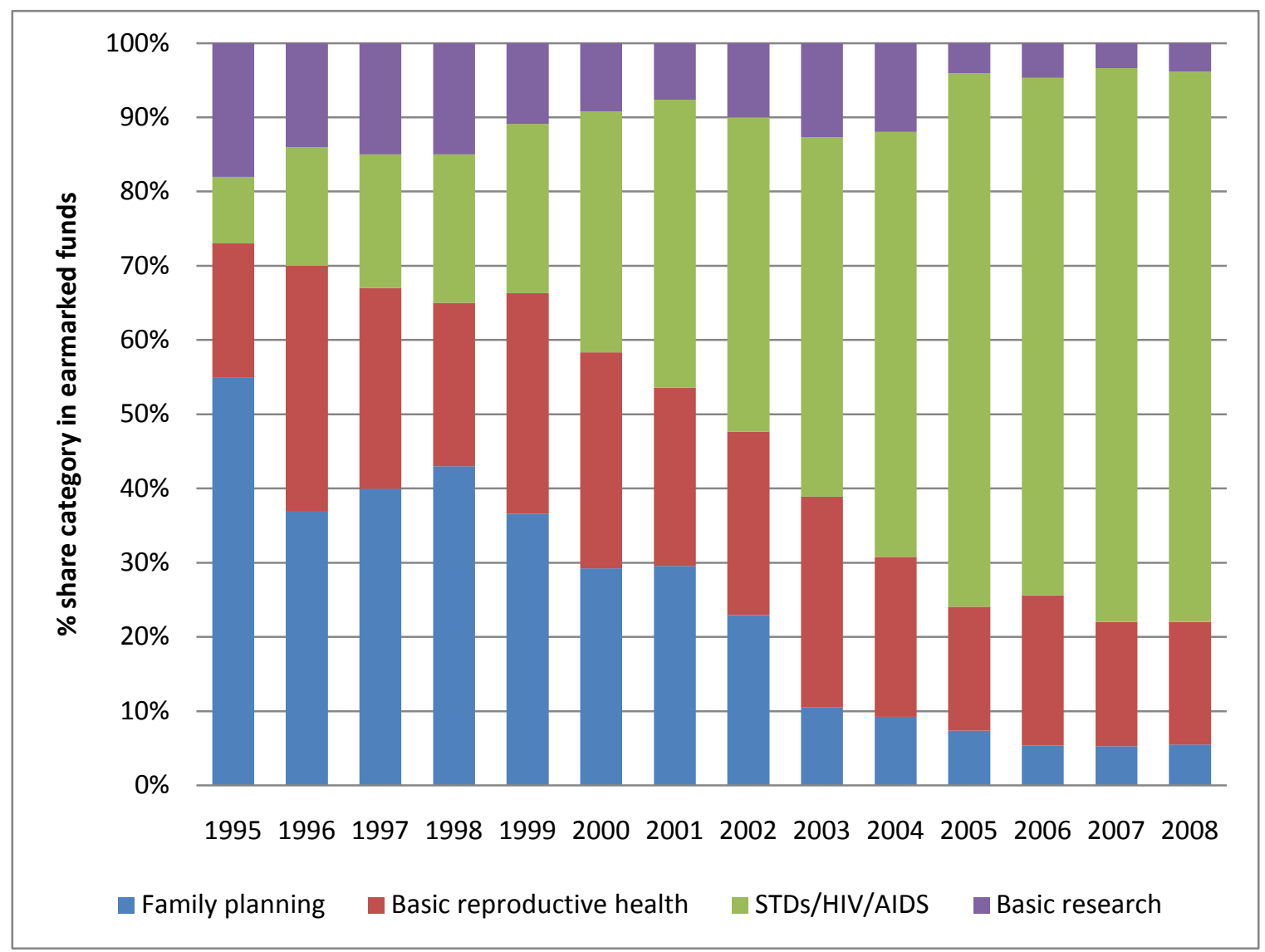

Source: UNFPA/NIDI database. 
Figure 3: Funding of UNFPA from USAID, 1968-2010 (in millions of U.S. dollars)

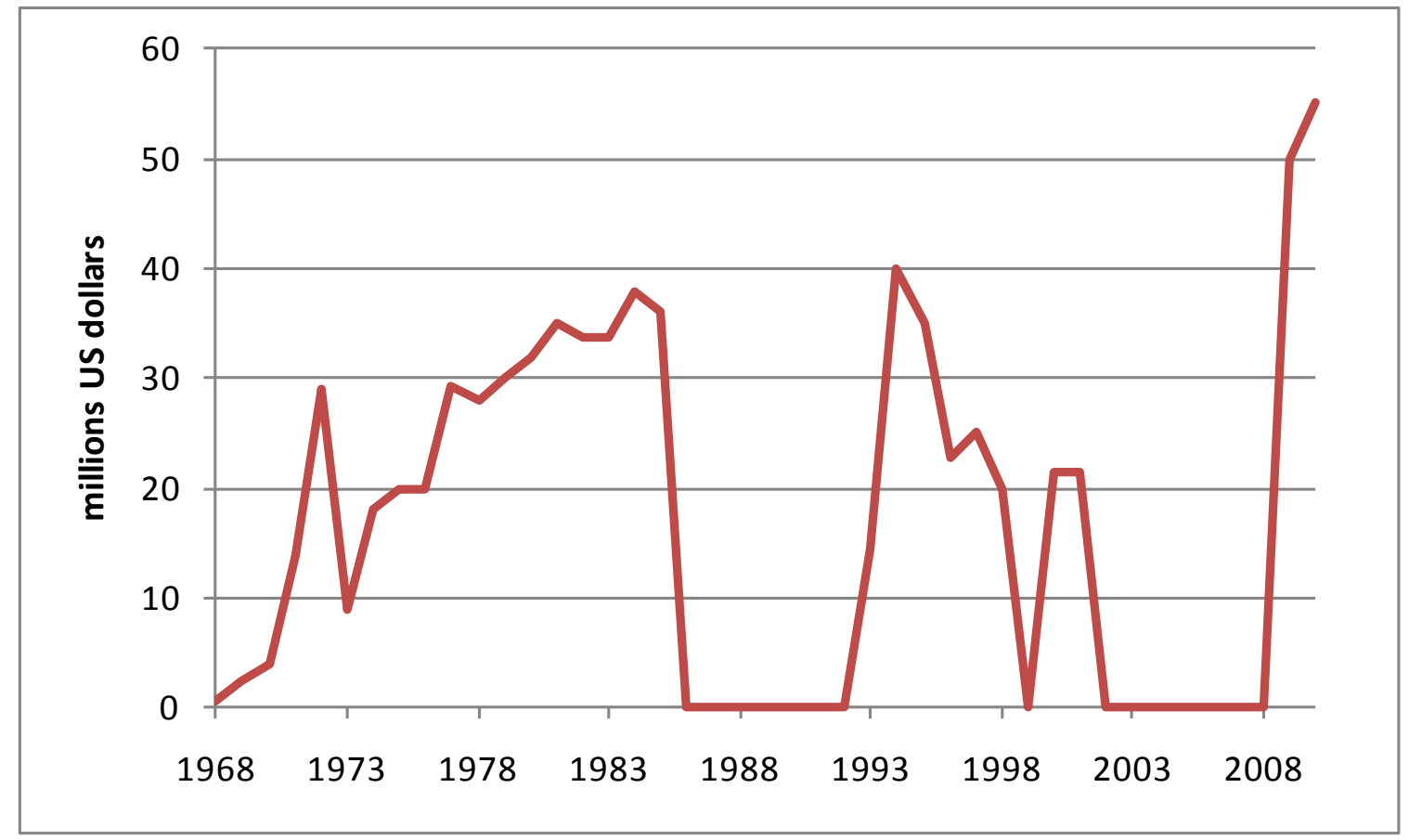

Source: Population Action International (2010). 